\title{
A pathological study of the association between Lewy body disease and Alzheimer's disease
}

\author{
W R G GIBB, * C Q MOUNTJOY, $\dagger$ D M A MANN, $\ddagger$ A J LEES* \\ From the Department of Neuropathology, ${ }^{*}$ National Hospitals for Nervous Diseases, Maida Vale, London; \\ St Andrew's Hospital, $\uparrow$ Northampton; Department of Psychiatry, $\dagger$ Addenbrooke's Hospital, Cambridge and \\ Department of Pathology $\ddagger$ University of Manchester, Manchester, UK
}

SUMMARY The possibility of an association between Parkinson's disease and Alzheimer's disease has been examined by studying the age-specific prevalence of Lewy bodies in the substantia nigra in a group of 273 control cases without Parkinson's disease and 121 cases of Alzheimer's disease. The substantia nigra was also studied in 14 cases of Down's syndrome, 13 of which had cortical Alzheimer pathology. Twelve $(7.8 \%)$ of the controls aged over 60 years showed nigral Lewy bodies. There was mild nerve cell degeneration and/or an extranigral distribution of Lewy bodies, suggestive of presymptomatic Parkinson's disease. Twenty five (22.5\%) of the Alzheimer's disease cases over 60 years showed Lewy bodies, but only $14(14.0 \%)$ of these had mild nigral cell loss consistent with presymptomatic Parkinson's disease. No case of Down's syndrome had Lewy bodies. Counts of tangles and plaques in hippocampus, frontal and temporal cortex were lower in cases of Alzheimer's disease with Lewy bodies compared with those without, but cortical choline acetyltransferase (ChAT) activities were similar. This suggests that Lewy body degeneration in the nucleus basalis of Meynert contributes to the deficit of cortical ChAT, but not to the cortical Alzheimer pathology. The relatively small difference in the prevalence of Lewy bodies between controls and Alzheimer's disease could be explained by the additive effects of Lewy body and tangle pathology causing dementia, rather than a greater than chance association between Parkinson's disease and Alzheimer's disease.

Pathological studies have suggested that cortical neurofibrillary tangles and neuritic plaques are associated more frequently with Lewy bodies in the brainstem than could be explained on the basis of chance. ${ }^{1-6}$ If correct this has two main implications. Firstly, that Alzheimer pathology may explain the increased prevalence of dementia in Lewy body-Parkinson's disease.' Secondly, that Alzheimer's disease and Parkinson's disease may share pathogenetic or aetiological factors.

Most studies have examined the frequency with which Alzheimer's disease complicates Parkinson's disease, and depend on the accuracy and interpretation of quantitative assessments of tangles and plaques. ${ }^{8}$ Unfortunately there is no clear-cut quantitative threshold for the pathological diagnosis of Alzheimer's disease. ${ }^{9}$ In contrast, the presence of one or more Lewy bodies in sections of substantia nigra

Address for reprint requests: Dr W R G Gibb, Dept of Neurology, Guy’s Hospital, London SEI 9RT, UK.

Received 24 June 1988 and in revised form 24 September 1988. Accepted 27 September 1988 of normal persons, aged over 50 years, is usually associated with degrees of nigral cell loss intermediate between normal and Parkinson's disease ${ }^{10}$ and an extranigral distribution of Lewy bodies identical to that found in Parkinson's disease." This suggests that such cases represent a presymptomatic phase of Parkinson's disease and are consistent with the observation that striatal dopamine levels fall below $20 \%$ of normal values before symptoms develop..$^{1213}$ We have therefore compared the size of this "at risk" Parkinson's disease population (presymptomatic Parkinson's disease) in a group of 273 controls and 121 cases of Alzheimer's disease. In addition the substantia nigra in 14 cases of Down's syndrome was examined for Lewy bodies, because of its established association with the pathology of Alzheimer's disease. ${ }^{14-17}$

\section{Materials and methods}

Brains were examined from patients with Alzheimer's disease, Down's syndrome and a control population. The group of 121 cases of Alzheimer's disease were collected in three laboratories and therefore identified as Series 1 to 3. Forty 
Fig 1 Lewy body (eosinophilic body with halo) in pigmented cell of the substantia nigra. H\&E stain, $\times 8200$.

cases in Series 1 were identified as having Alzheimer's disease on the basis of large numbers of neocortical plaques and tangles. The patients had documented histories of dementia and their brains were collected after death from psychiatric and general hospitals. In Series 2 (33 cases) and Series 3 (48 cases) the brains were obtained at necropsy from patients with progressive dementia residing in psychiatric hospitals. The neuropathological findings of numerous plaques and tangles in the neocortex, in the absence of significant cerebrovascular disease, confirmed the diagnosis of Alzheimer's disease. In the group of 14 cases of Down's syndrome, six were known to be trisomy 21 and all but one showed Alzheimer pathology.

Two hundred "control" brains were obtained from two neuropathology laboratories (Group 1). These patients had died from neurological disorders other than Parkinsonian syndromes and Alzheimer's disease. The remaining 73 cases (Group 2) were collected from a general hospital necropsy service, specifically for the purpose of the study.

Every brain was immersion fixed in formol-saline for a minimum period of three weeks. One block of substantia nigra was cut perpendicular to the axis of the brainstem. Blocks of locus coeruleus, nucleus basalis of Meynert, hippocampus, middle temporal gyrus (Brodmann area 21) and frontal cortex (Brodmann area 10) were also prepared. Sections of paraffin wax-embedded blocks were cut at thicknesses varying from $5 \mu \mathrm{m}$ to $20 \mu \mathrm{m}$. Most were cut at $7 \mu \mathrm{m}$, but the brains of Alzheimer's disease Series 2 and those of Down's syndrome were cut at $5 \mu \mathrm{m}$, and those of Alzheimer's disease Series 3 cut at $16 \mu \mathrm{m}$. Haematoxylin and eosin (H\&E) stain was used in every case with adjacent cortical sections stained with Bielschowsky silver impregnation (Alzheimer's disease Series 1), modified Palmgren stain ${ }^{18}$ (Alzheimer's disease Series 2) or the Glees and Marsland modification of the Bielschowsky silver method (Alzheimer's disease Series 3). Additional sections were stained with Nissl cresyl violet.

Examination of the substantia nigra required an eyepiece graticule used at $\times 400$ magnification moved in parallel sweeps across the section. The amount of free melanin and cell destruction were estimated as mild, moderate or severe. The severity of cell loss was also estimated as mild (60-90\% of cells remaining), moderate (20-60\% of cells remaining) or severe (0-20\% of cells remaining), and the cut off point for symptoms of Parkinson's disease was taken as $40 \%$ of cells remaining. ${ }^{1920}$ Each cell was examined for Lewy bodies, which were defined as intracytoplasmic, eosinophilic bodies with haloes (fig 1). Sections of locus coeruleus, nucleus basalis, hippocampus and cerebral cortex were examined cell by cell for Lewy bodies.

In Series 2 the Palmgren stain was used to count plaques and tangles in sections of middle temporal gyrus ( $5 \mu \mathrm{m}$ thick) by the "nearest neighbour distance" method described by Aherne and Diggle. ${ }^{21}$ This technique measures distance between cells and provides a density measurement so that results are expressed as numbers of cells per area. ${ }^{22}$ In the 
Table 1 Age-specific prevalence of Lewy bodies in Alzheimer's disease

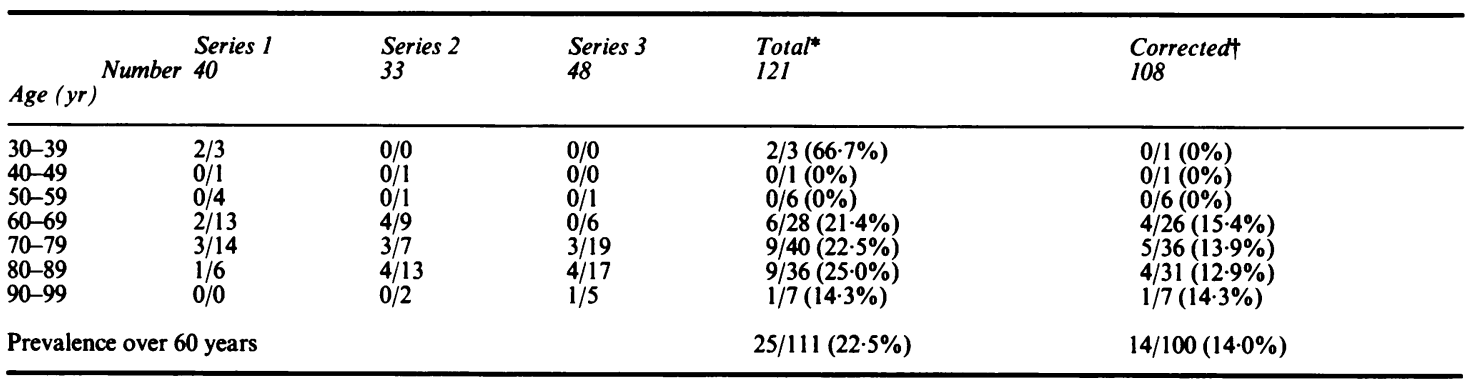

*Includes "Parkinsonian" cases.

tIncidental cases only.

The numerator is the number of Alzheimer's disease cases with Lewy bodies; the denominator is the total number of Alzheimer's disease cases. Two cases in Series 1 of unknown age have been included in the seventh decade.

hippocampus plaques and tangles were counted in whole sections. In Series 3 the Glees stain was used on sections (16 $\mu \mathrm{m}$ thick) of frontal cortex and middle temporal gyrus for plaque and tangle counts by the methods described by Mountjoy et al..$^{23}$ The plaque count was derived from a combination of two methods which showed a high degree of correlation. One was a random plaque count where plaques were counted in parallel strips perpendicular to the cortical surface, the other a selected plaque count derived from counts found in areas of maximal plaque density. The frequency of tangles was estimated on a four-point scale $(0=$ absent, $1=$ slight, $2=$ moderate, $3=$ severe $)$ after the method of Corsellis. ${ }^{24}$ It has been demonstrated that these tangle estimates when done on two separate occasions show a high degree of correlation. ${ }^{23}$

Samples of middle temporal gyrus (Brodmann area 21)

Fig 2 Eosinophilic inclusion present in the subiculum in Patient 3. Unlike most Lewy bodies the demarcation between "body" and "halo" is abrupt (arrow), and the "halo" wide and pale. H\&E stain, $\times 8200$. 
(a)
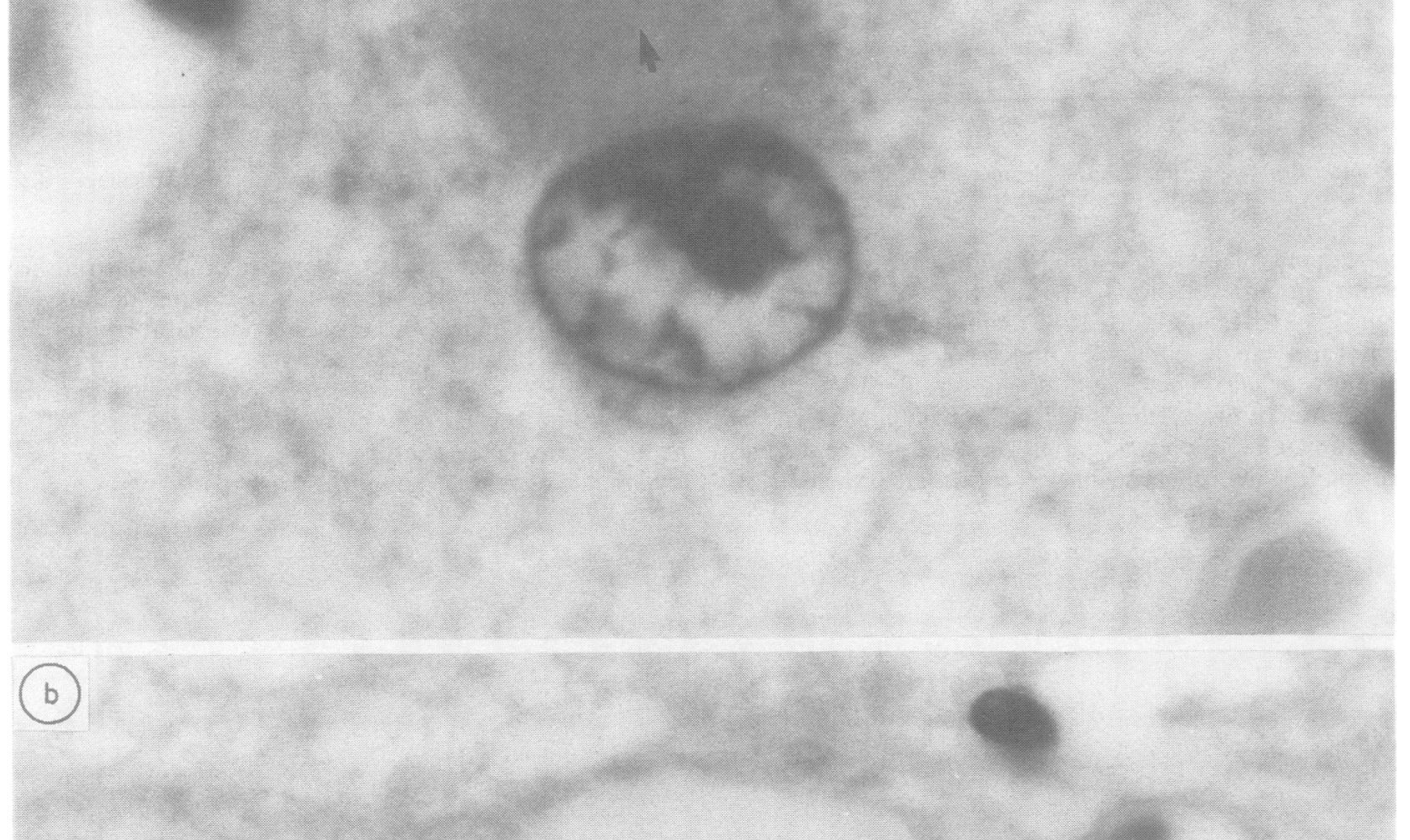
Table 2 Alzheimer's disease Series 2. Estimations of tangles and plaques in the middle temporal gyrus (Brodmann area 21) and hippocampus in 26 cases of Alzheimer's disease with and without Lewy bodies in the substantia nigra

\begin{tabular}{llll}
\hline & $\begin{array}{l}\text { Lewy body } \\
\text { neg cases (18) } \\
\text { mean age } \\
74.6 \text { yr }\end{array}$ & $\begin{array}{l}\text { Lewy body } \\
\text { pos cases (8) } \\
\text { mean age } \\
77.5 y r\end{array}$ & $\begin{array}{l}\text { Difference } \\
\text { as per cent } \\
\text { of Lewy } \\
\text { body neg } \\
\text { cases }\end{array}$ \\
\hline $\begin{array}{c}\text { Temporal cortex } \\
\text { plaques }\end{array}$ & 18.6 (SD 10.9) & 13.6 (SD 5.2) & 27 \\
$\begin{array}{c}\text { Temporal cortex } \\
\text { tangles }\end{array}$ & 19.1 (SD 11.3) & 13.6 (SD 5.8) & 29 \\
$\begin{array}{c}\text { Hippocampus } \\
\text { plaques }\end{array}$ & 56.4 (SD 62.6) & 37.6 (SD 28.4) & 33 \\
$\begin{array}{c}\text { Hippocampus } \\
\text { tangles }\end{array}$ & 145.1 (SD 91.7) & 131.3 (SD 58.0) & 10 \\
\hline
\end{tabular}

Temporal cortex plaque and tangle counts expressed as number per $\mathrm{mm}^{2}$.

Hippocampal plaque and tangle counts expressed as number per section.

and frontal cortex (Brodmann area 10) were used for measurements of choline acetyltransferase (ChAT) activities. $^{25}$

\section{Results}

In Alzheimer's disease Series 1, mean age 68.6 years, there were three patients, aged 38, 38 (Patients 1 and 2) and 36 years at death, whose mother or sibling also had dementia (table 1). Lewy bodies were present in the substantia nigra in eight cases, in three of which, aged 38, 38 (Patients 1 and 2 ) and 80 years, the severity of nigral cell loss was sufficient to produce Parkinsonian features. One of the patients aged 38 years (Patient 1) exhibited a mask-like face and had numerous falls. The patient aged 80 years had muscular rigidity of the arms and a rest tremor of the right arm. As the association of Lewy bodies and nigral cell loss in excess of $60 \%$ is compatible with Parkinson's disease, these patients were not included as cases of presymptomatic disease.

The brain of Patient 1, a male of 38 years, showed severe neocortical changes of Alzheimer's disease with very numerous tangles and some amyloid deposits in the substantia nigra and ventral tegmental area. A single Lewy body was seen in the lateral substantia nigra zona compacta but none were found in the locus coeruleus, dorsal vagal nucleus or nucleus basalis. The brain of Patient 2, a female aged 38 years, showed tangles in the substantia nigra and locus coeruleus, with amyloid plaques in the substantia nigra, medulla, hypothalamus and nucleus basalis, and plaques alone in the thoracic spinal cord. Multiple Lewy bodies were present in the substantia nigra but not in the cerebral cortex, dorsal nucleus of the vagus, nucleus basalis or locus coeruleus. In another patient (Patient 3), a woman aged 61 years, there was severe cortical and
Table 3 Alzheimer's disease Series 3. Estimations of tangles and plaques, and of choline acetyltransferase (ChAT) in the frontal cortex (Brodmann area 10) and middle temporal gyrus (Brodmann area 21) in 48 cases of Alzheimer's disease with and without Lewy bodies in the substantia nigra

\begin{tabular}{|c|c|c|c|}
\hline & $\begin{array}{l}\text { Lewy body neg } \\
\text { cases }(40) \\
\text { mean age } \\
74.0 \mathrm{yr}\end{array}$ & $\begin{array}{l}\text { Lewy body } \\
\text { pos cases }(8) \\
\text { mean age } \\
82.0 \mathrm{yr}\end{array}$ & $\begin{array}{l}\text { Difference as } \\
\text { percent of } \\
\text { heavy body } \\
\text { negative } \\
\text { cases }\end{array}$ \\
\hline $\begin{array}{l}\text { B10 plaque count } \\
\text { B10 tangle count } \\
\text { B21 plaque count } \\
\text { B21 tangle count } \\
\text { B10 ChAT } \\
\text { B21 ChAT }\end{array}$ & $\begin{array}{l}1.00(\text { SD } 0.95) \\
2.10(\text { SD 2.00) } \\
1.07 \\
2.17 \\
4.03(\text { SD 2.09) } \\
2.83(\text { SD 2.34) }\end{array}$ & $\begin{array}{l}0.44(\text { SD } 0.35) \\
1.04(\text { SD } 1.1) \\
0.38 \\
1.9 \\
4.20(\text { SD 2.26) } \\
2.46(\text { SD } 1.49)\end{array}$ & $\begin{array}{l}56 \cdot 0 \\
50 \cdot 5 \\
64 \cdot 5 \\
12 \cdot 4 \\
- \\
-\end{array}$ \\
\hline
\end{tabular}

Plaque counts derived from two measurements (see text). Tangle counts on scale $0-4$, absent-severe.

ChAT units, $\mu \mathrm{mol} / \mathrm{h} / \mathrm{g}$ protein.

subcortical Alzheimer's disease with granulovacuolar degeneration in the ventral tegmental area. One isolated inclusion, vaguely resembling a Lewy body, was found in the subiculum with none elsewhere (fig 2).

Alzheimer's disease Series 2, mean age 75.4 years, was seven years older than Series 1 (table 1). The mother of one patient, a 48 year old woman, had histologically proven Alzheimer's disease. Lewy bodies were present in the substantia nigra of 11 cases, in seven of which there was moderate or severe loss of pigmented cells compatible with Parkinson's disease. Of the remaining four cases with Lewy bodies one had little cell loss and three had mild cell loss.

The nucleus basalis was examined in eight cases with nigral Lewy bodies and six Lewy body negative cases. Lewy bodies were found here in the Lewy body positive cases, in which the degree of cell loss ranged from moderate to severe. In Lewy body negative cases the degree of nucleus basalis cell loss was mild to noderate. Lewy bodies were found in the parahippocampal gyrus in six of eight Lewy body positive cases; and in eight of nine cases Lewy bodies were present in the middle temporal gyrus. In the single case without Lewy bodies in the middle temporal gyrus only a small section was examined. In the cerebral cortex cells that were swollen with ill-defined pale areas or inclusions were more numerous than those containing Lewy bodies (fig 3). Estimations of tangles and plaques in the temporal lobe and hippocampus showed consistently lower mean values (by $10 \%$ to $33 \%$ ) for the Lewy body positive cases compared with cases of Alzheimer's disease alone (table 2).

Alzheimer's disease Series 3, mean age 78.6 years, was 10 years older than Series 1 (table 1). Lewy bodies were found in the substantia nigra in eight cases, in three of which nigral cell loss was moderate and in five it was mild. They also showed Lewy bodies in the locus 
Table 4 Selected clinical and pathological details in 14 cases of Down's syndrome

\begin{tabular}{llll}
\hline Patient & $\begin{array}{l}\text { Age }(y r) \\
\text { sex }\end{array}$ & $\begin{array}{l}\text { Mental age } \\
\text { IQ* }\end{array}$ & $\begin{array}{l}\text { Brain } \\
\text { weight }(g)\end{array}$ \\
\hline 1 & $31 \mathrm{M}$ & $2 /<30$ & 1050 \\
2 & $37 \mathrm{~F}$ & $<2 / 30$ & 1045 \\
3 & $41 \mathrm{M}$ & - & 1245 \\
4 & $53 \mathrm{M}$ & $3 / 30$ & 870 \\
5 & $57 \mathrm{M}$ & $4 /-$ & Not recorded \\
6 & $59 \mathrm{M}$ & $4 /<30$ & 950 \\
7 & $60 \mathrm{M}$ & - & 920 \\
8 & $60 \mathrm{~F}$ & $<2 /<30$ & 965 \\
9 & $62 \mathrm{~F}$ & $6 / 42$ & 850 \\
10 & $62 \mathrm{~F}$ & $3 /<30$ & 960 \\
11 & $64 \mathrm{M}$ & $2 /<30$ & 940 \\
12 & $64 \mathrm{M}$ & $<2 /<30$ & 940 \\
13 & $65 \mathrm{M}$ & $3.5 /<30$ & Not recorded \\
14 & $71 \mathrm{M}$ & $2 / 44$ & 1130 \\
\hline
\end{tabular}

Paraffin sections were prepared at $5 \mu \mathrm{m}$ thickness and stained for senile plaques and neurofibrillary tangles using a modified Palmgren's silver technique. ${ }^{18}$

*Based on the Wechsler Intelligence Test.

coeruleus. The middle temporal gyrus contained isolated Lewy bodies in two of the eight Lewy body cases, but none were found in the frontal pole cortex. The middle temporal gyrus was examined in 21 cases without nigral Lewy bodies and the frontal pole cortex in 31 cases without nigral Lewy bodies, and no Lewy bodies were found. Counts of tangles and plaques in the frontal and temporal cortex were $12 \%$ to $56 \%$ lower in the Lewy body positive cases. In contrast there were no differences in activities of ChAT (table $3)$.

Data on the age-specific prevalence of Lewy bodies in the three series of Alzheimer's disease were combined (table 1). The series were contaminated by a total of 13 cases in which nigral cell loss was severe enough to produce Parkinsonian features. Such patients may have been selected into these hospitalbased studies because of difficulties with mobility. Their exclusion leaves 108 patients in which the prevalence of incidental Lewy body disease was $13 \%$ to $15 \%$ per decade in the seventh to tenth decades.

In the cases of Down's syndrome Patient 1 had no cerebral plaques or tangles and Patient 2 had numerous plaques, but few tangles (table 4). The remaining 12 cases had numerous neocortical plaques and tangles. In none of them were Lewy bodies found by searching one or two sections of substantia nigra.

A total of 14 of 273 "control" brains contained Lewy bodies in the substantia nigra, with similar proportions in the two groups examined (table 5). In eight of these 14 cases cell loss in the substantia nigra was mild in severity, but in six cases there was no obvious cell loss, although amounts of extraneuronal melanin were abnormally increased in three. As in Parkinson's disease Lewy bodies were also found in
Table 5 Age-specific prevalence of Lewy bodies in "control" brains

\begin{tabular}{llll}
\hline $\begin{array}{l}\text { Age group } \\
\text { yr) }\end{array}$ & Group 1 & Group 2 & Total \\
\hline $10-19$ & $0 / 5$ & $0 / 0$ & $0 / 5$ \\
$20-29$ & $0 / 16$ & $0 / 1$ & $0 / 17$ \\
$30-39$ & $0 / 15$ & $0 / 2$ & $0 / 17$ \\
$40-49$ & $0 / 26$ & $0 / 1$ & $0 / 27$ \\
$50-59$ & $2 / 48(4 \cdot 2 \%)$ & $0 / 5(0 \%)$ & $2 / 53(3 \cdot 8 \%)$ \\
$60-69$ & $3 / 51(5 \cdot 9 \%)$ & $0 / 13(0 \%)$ & $3 / 64(4 \cdot 7 \%)$ \\
$70-79$ & $2 / 23(8 \cdot 7 \%)$ & $2 / 20(10 \cdot 0 \%)$ & $4 / 43(9 \cdot 3 \%)$ \\
$80-89$ & $2 / 14(14 \cdot 3 \%)$ & $3 / 25(12 \cdot 0 \%)$ & $5 / 39(12 \cdot 8 \%)$ \\
$90-99$ & $0 / 1$ & $0 / 6$ & $0 / 7$ \\
$100-109$ & $0 / 1$ & $0 / 0$ & $0 / 1$ \\
Prevalence & & & \\
over 60 & $7 / 90(7 \cdot 8 \%)$ & $5 / 64(7 \cdot 8 \%)$ & $12 / 154(7 \cdot 8 \%)$ \\
years & & & \\
\hline
\end{tabular}

The numerator is the number of Lewy body cases (incidental Lewy body disease), the denominator is the total number of cases examined.

the locus coeruleus, dorsal vagal nucleus and nucleus basalis.

\section{Discussion}

Most cases of Alzheimer's disease with Lewy bodies in the substantia nigra showed Lewy bodies in one or more locations elsewhere in the brain. They were most $\mathbb{1}$ commonly found in the locus coeruleus, nucleus basalis and cerebral cortex reflecting the pattern seen $\circ$ in Parkinson's disease. The age-specific prevalence of presymptomatic Parkinson's disease occurring in Alzheimer's disease was similar to that in a group of control patients with neurological and non-co neurological disorders. However, small differences? remained in the seventh and eighth decades, despite excluding cases of combined Lewy body disease and Alzheimer's disease, with nigral cell loss sufficient to produce Parkinsonian features.

In Alzheimer's disease Series 2 and 3 the tangle and plaque counts in hippocampus, temporal and frontal cortex were consistently lower in those cases with brainstem Lewy bodies, with the smallest difference being for hippocampal tangle counts (Series 2). In contrast, the activities of ChAT in frontal and temporal cortex (Series 3 ) were no different suggesting that Lewy body degeneration in the nucleus basalis contributed to the cortical cholinergic deficit, but not to the number of cortical plaques and tangles. This observation agrees with recent studies which have not always found Alzheimer cortical pathology in cases of Parkinson's disease with dementia, although the nucleus basalis may be depleted and activities of cortical ChAT reduced. ${ }^{26-28}$ The differences in methodology applied to the three Series are not likely to have influenced outcome, but the consistent nature of the results between the Series tends to strengthen the observations. 


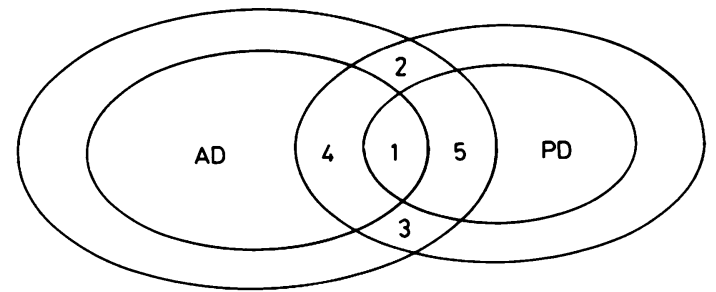

Fig 4 Interactions between Alzheimer's disease (AD) and Parkinson's disease (PD). The inner ovals represent symptomatic cases of Alzheimer's disease and Parkinson's disease, the outer ovals include presymptomatic cases. Area 1 represents overlap between Alzheimer's disease and Parkinson's disease equivalent to the chance concurrence of these disorders. Areas 2 and 3 represent patients with modest Alzheimer pathology and nigral Lewy bodies, many of whom have dementia, but not Parkinson's disease. Area 4 represents patients with Alzheimer's disease and nigral Lewy bodies, but no Parkinson's disease. Area 5 represents patients with Parkinson's disease and modest Alzheimer pathology, many of whom have dementia.

In post-mortem studies of Alzheimer's disease there is a slight increase in the prevalence of incidental Lewy bodies, probably because of the inclusion of patients with dementia and cell loss in the nucleus basalis resulting from a combination of Lewy body disease with mild Alzheimer pathology (presymptomatic or borderline cases of Alzheimer's disease) (fig 4). The inclusion of cases of cortical Lewy body disease which is associated with dementia, even with little or no Alzheimer pathology ${ }^{29-31}$ may be another explanation. It is of note that the prevalence of cortical Lewy bodies in Series 2 and 3 was $59 \%(10 / 17)$. A slightly lower prevalence of $30 \%(16 / 54)$ has been found in unselected cases of Parkinson's disease. ${ }^{29}$ Finally, a very small factor contributing to the excess frequency of Lewy bodies may be a reduced life expectancy, resulting from the co-existent pathologies (Lewy bodies and Alzheimer pathology) responsible for the dementia, shifting the age-specific prevalence of Lewy bodies to the left (fig 5).

The absence of Lewy bodies complicating the Alzheimer pathology of Down's syndrome provides additional support for the notion that Alzheimer's disease and Lewy body disease are not generally associated.

In a previous study Woodard" collected 96 brains with pathological features of Alzheimer's disease from persons aged over 50 years. In ten $(10.4 \%)$ cases Lewy bodies were present in the substantia nigra or other locations in the brainstem. This can be compared with his prevalence figure of $8.8 \%(17 / 194)$ for all persons aged over 50 years, although a couple of these had Parkinsonian features. Another study consisted of 128 cases of senile dementia of the Alzheimer type and 68

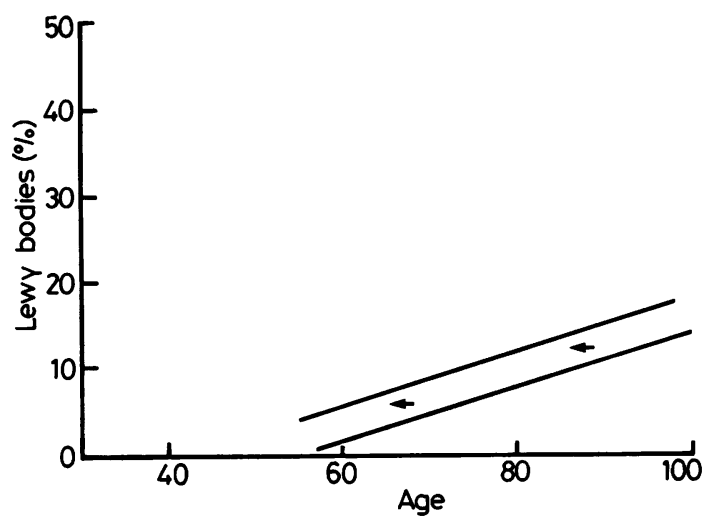

Fig 5 Left-shift of the age-specific prevalence of Lewy bodies in Alzheimer's disease, because of dual pathologies responsible for dementia, and consequent reduced life expectancy.

cases of Alzheimer's disease, with mean age at death of 80.7 years and 65.4 years respectively..$^{32}{ }^{33}$ Lewy bodies were found in the substantia nigra or locus coeruleus in $15 \%$ or $22 \%$ respectively of the total (mean age 75.4 years), compared with a prevalence of $10 \%$ or $16 \%$ in 180 controls (mean age 74.3 years). These authors concluded that there was no evidence for an excess number of Lewy bodies in Alzheimer's disease.

In this study Patients 1 and 2 cannot be explained on the basis of additive lesions and selection bias. They showed familial Alzheimer's dementia presenting at a young age, with Lewy bodies present in the substantia nigra at death. Another young patient, aged 39 years, has been reported with Lewy body disease and Alzheimer's disease, but without other affected family members. $^{34}$ Thus there are a few rare, sometimes familial, cases where the pathologies of Alzheimer's disease and Lewy body disease coexist.

In Patient 3 the severe cortical pathology of Alzheimer's disease was associated with an isolated cortical neuronal inclusion resembling a Lewy body, in the absence of Lewy bodies in the brainstem. However, it lacked the precise morphology of a cortical Lewy body, and occurred in isolation in a region where cortical Lewy bodies are less plentiful. Furthermore cortical Lewy bodies have never been observed in the absence of brainstem Lewy bodies. Current evidence suggests that dementia with cortical Lewy bodies always forms part of the spectrum of Parkinson's disease. ${ }^{29}$

This study fails to provide support for a greater than chance association between Alzheimer's disease and Parkinson's disease, except in rare cases. These rare cases join a small group of other disorders associated with Lewy bodies. ${ }^{35-40}$ The study emphasises the interaction of three major pathologies responsible for 
dementia in Parkinson's disease: Alzheimer's disease, Lewy bodies and cell loss in the nucleus basalis, and cortical Lewy bodies.

WRGG was a Medical Research Council Training Fellow. We thank Dr R O Barnard and Professor P L Lantos for permission to study their cases, and Dr $M$ N Rossor for providing the ChAT data and for helpful discussion.

\section{References}

1 Alvord EC, Forno LS, Kusske JA, Kauffman RJ, Rhodes JS, Goetowski CS. The pathology of parkinsonism: A comparison of degenerations in cerebral cortex and brainstem. Adv Neurol 1974;5:175-93.

2 Hakim AM, Mathieson G. Dementia in Parkinson disease: A neuropathological study. Neurology 1979;29:1209-14.

3 Boller F, Mitzutani T, Roessman U, Gambetti P. Parkinson disease, dementia and Alzheimer disease: clinicopathological correlations. Ann Neurol 1980;7:329-35.

4 Joachim CL, Morris JH, Selkoe DJ. Clinically diagnosed Alzheimer's disease: autopsy results in 150 cases. Ann Neurol 1988;24:50-6.

5 Ditter SM, Mirra SS. Parkinson's disease in Alzheimer's disease: a neuropathologic and clinical study. Neurology 1986;36 (suppl 1): 225 .

6 Leverenz J, Sumi SM. Parkinson's disease in patients with Parkinson's disease. Arch Neurol 1986;43:662-4.

7 Brown RG, Marsden CD. How common is dementia in Parkinson's disease? Lancet 1984;ii:1262-5.

8 Tomlinson BE, Blessed G, Roth M. Observations on the brains of demented old people. J Neurol Sci 1970;11:205-42.

9 Mann DMA, Yates PO, Marcynuik B. Age and Alzheimer's disease. Lancet 1984;i:281-2.

10 Forno LS. Pathology of Parkinsonism. A preliminary report of 24 cases. J Neurosurg 1966;24. Suppl:266-71.

11 Woodard JS. Concentric hyaline inclusion body formation in mental disease. Analysis of twenty-seven cases. J Neuropathol Exp Neurol 1962;21:442-9.

12 Bernheimer $\mathrm{H}$, Birkmayer $\mathrm{W}$, Hornykiewicz $\mathrm{O}$, Jellinger $\mathrm{K}$, Seitelberger F. Brain dopamine and the syndromes of Parkinson and Huntington. J Neurol Sci 1973;20:415-55.

13 Hornykiewicz $\mathrm{O}$. Brain neurotransmitter changes in Parkinson's disease. In: Marsden CD, Fahn S, eds. Movement Disorders. London: Butterworth, 1982:41-58.

14 Olson MJ, Shaw CM. Presenile dementia and Alzheimer's disease in mongolism. Brain 1969;92:147-56.

15 Wisniewski KE, Dalton AJ, Crapper McLachlan DR, Wen GY, Wisniewski HM. Alzheimer's disease in Down's syndrome: clinicopathologic studies. Neurology 1985;35:957-61.

16 Wisniewski KE, Wisniewski HM, Wen GY. Occurrence of neuropathological changes and dementia of Alzheimer's disease in Down's syndrome. Ann Neurol 1985;17:278-82.

17 Godridge H, Reynolds GP, Czudek C, Calcutt NA, Benton M. Alzheimer-like neurotransmitter deficits in adult Down's syndrome brain tissue. J Neurol Neurosurg Psychiatry 1987;50: 775-8.

18 Cross RG. Demonstration of neurofibrillary tangles in paraffin sections: a quick and simple method using a modification of Palmgren's method. Med Lab Sci 1982;39:67-9.
19 Pakkenberg H, Brody H. The number of nerve cells in the substantia nigra in paralysis agitans. Acta Neuropathol 1965;5:320-4.

20 Gibb WRG, Lees AJ. The significance of the Lewy body in the diagnosis of idiopathic Parkinson's disease. Neuropathol Appl Neurobiol 1989;15:27-44.

21 Aherne WA, Diggle PJ. The estimation of neuronal population density by a robust distance method. J Microsc 1978;114: 285-93.

22 Mann DMA, Yates PO, Marcynuik B. Some morphometric observations on the cerebral cortex and hippocampus in presenile Alzheimer's disease, senile dementia of Alzheimer type and Down's syndrome in middle age. J Neurol Sci 1985;69: 139-59.

23 Mountjoy CQ, Roth M, Evans NJR, Evans HM. Cortical neuronal counts in normal elderly controls and demented patients. Neurobiol Ageing 1983;4:1-11.

24 Corsellis JAN. Mental illness and the Ageing Brain. Maudsley Monographs Number 9. London: Oxford University, 1962.

25 Rossor MN, Garrett NJ, Johnson AJ, Mountjoy CQ, Roth M, Iversen LL. A post-mortem study of the cholinergic and GABA systems in senile dementia. Brain 1982;105:313-30.

26 Gaspar P, Gray F. Dementia in idiopathic Parkinson's disease. A neuropathological study of 32 cases. Acta Neuropathol 1984;64:43-52.

27 Nakano I, Hirano A. Parkinson's disease: neuron loss in the nucleus basalis without concomitant Alzheimer's disease. Ann Neurol 1984;15:415-8.

28 Perry EK, Curtis M, Dick DJ, et al. Cholinergic correlates of cognitive impairment in Parkinson's disease: comparisons with Alzheimer's disease. $J$ Neurol Neurosurg Psychiatry 1985: 48:413-21.

29 Gibb WRG, Lees AJ. Dementia in Parkinson's disease. Lanceg 1987;i:861.

30 Clark AW, White CL, Manz HJ, et al. Primary degenerativ尺 dementia without Alzheimer pathology. Can J Neurol $S \Phi$ 1986;13 (suppl):462-70.

31 Sima AAF, Clark AW, Sternberger NA, Sternberger LA. Lew body dementia without Alzheimer changes. Can J Neurol Se 1986;13 (suppl):490-7.

32 Jellinger K, Grisold W. Cerebral atrophy in Parkinson syndrome Exp Brain Res 1982;(suppl 5):26-35.

33 Jellinger K, Riederer P. Dementia in Parkinson's disease and (pre)senile dementia of Alzheimer type: morphological aspects and changes in the intracerebral MAO activity. Adv Neurol 1984;40:199-210.

34 Gibb WRG, Esiri MM, Lees AJ. Clinical and pathological features of diffuse cortical Lewy body disease (Lewy body dementia). Brain 1987;110:1131-53.

35 Sigwald J, Lapresle J, Raverdy P, Recondo NJ. Atrophie cérébelleuse familiale avec association de lésions nigériennes et spinales. Presse Med 1964;72:557-62.

36 Sachdev HS, Forno LS, Kane CA. Joseph disease: a multisystem degenerative disorder of the nervous system. Neurology 1982;32:192-5.

37 Dooling EC, Schoene WC, Richardson EP. Hallervorden-Spatz syndrome. Arch Neurol 1974;30:70-83.

38 Hirano A, Kurland LT, Sayre GP. Familial amyotrophic lateral sclerosis. A subgroup characterised by posterior and spinocerebellar tract involvement and hyaline inclusions in the anterior horn cells. Arch Neurol 1967;16:232-43.

39 De Leon GA, Grover WD, Huff DS. Neuropathological changes in ataxia-telangiectasia. Neurology 1976;26:947-51.

40 Cobb WA, Marshall J, Scaravilli F. Long survival in subacute sclerosing panencephalitis. J Neuropathol Exp Neurol 1984;47:176-83. 